\title{
Concordance for Type 1 (insulin-dependent) and Type 2 (non-insulin-dependent) diabetes mellitus in a population-based cohort of twins in Finland
}

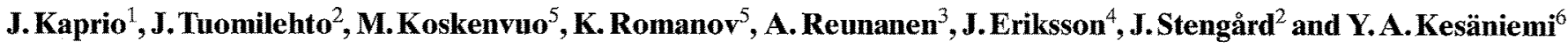 \\ ${ }^{2}$ Department of Public Health, University of Helsinki; ${ }^{2}$ Department of Epidemiology, National Public Health Institute; \\ ${ }^{3}$ Research Institute for Social Security, Social Insurance Institution; ${ }^{4}$ Department of Medicine, Helsinki University Hospital, Helsinki: \\ ${ }^{5}$ Department of Public Health, University of Turku, Turku and ${ }^{6}$ Department of Medicine, University of Oulu, Oulu, Finland
}

\begin{abstract}
Summary. We studied the cumulative incidence, concordance rate and heritability for diabetes mellitus in a nationwide cohort of 13,888 Finnish twin pairs of the same sex. The twins were born before 1958 and both co-twins were alive in 1967. Data on diabetes were derived through computerized record linkage from death certificates, the National Hospital Discharge Register and the National Drug Register. Records were reviewed in order to assign a diagnostic category to the 738 diabetic patients identified. Of these patients 109 had Type 1 (insulin-dependent) diabetes, 505 Type 2 (non-insulin-dependent) diabetes, 46 gestational diabetes, 24 secondary diabetes, 38 impaired glucose tolerance and 16 remained unclassified. The cumulative incidence of diabetes was $1.4 \%$ in men and $1.3 \%$ in women aged $28-59$ years and
\end{abstract}

$9.3 \%$ and $7.0 \%$ in men and women aged 60 years and over, respectively. The cumulative incidence did not differ between monozygotic and dizygotic twins. The concordance rate for Type 1 diabetes was higher among monozygotic ( $23 \%$ probandwise and $13 \%$ pairwise) than dizygotic twins (5\% probandwise and $3 \%$ pairwise). The probandwise and pairwise concordance rates for Type 2 diabetes were $34 \%$ and $20 \%$ among monozygotic tiwns and $16 \%$ and $9 \%$ in dizygotic twins, respectively. Heritability for Type 1 diabetes was greater than that for Type 2 where both genetic and environmental effects seemed to play a significant role.

Key words: Diabetes mellitus, twins, prevalence, concordance, heritability.
Both Type 1 (insulin-dependent) and Type 2 (non-insulin dependent) diabetes mellitus result from an interaction between genetic and environmental factors, but the factors responsible for diabetes, as well as the mode of inheritance, are not known for either disease $[1,2]$. Comparison of concordance in monozygotic and dizygotic twins provides information regarding relative importance of genetic and environmental factors in the aetiology of diabetes. Earlier twin studies have suggested that among monozygotic twins the concordance for Type 2 diabetes is very high, ranging from $55 \%$ to almost $100 \%$ whereas the concordance for Type 1 diabetes is lower, ranging from $25 \%$ to $50 \%$ [3-9]. No study has estimated the concordance for Type 1 and Type 2 diabetes among monozygotic and dizygotic twins in the same population. As the degree of the relationship decreases from monozygotic twin to first degree relatives to second degree to third degree relatives, the risks for Type 1 and Type 2 diabetes tend to decrease in a non-linear fashion [10].

Twin studies of diabetes have usually ascertained the twins through reporting of the diagnosis of the diabetic twin. Previously we have reported that the selection bias in twin studies is likely to influence estimated heritability for chronic diseases in geographically or otherwise restricted population samples [11]. Consequently the concordance rates may have been overestimated due to a selection or reporting bias.

Finland has the highest incidence of childhood Type 1 diabetes [12,13], and the prevalence of Type 2 diabetes in the elderly is comparable with the highest reported prevalences in other western countries [14,15]. Since Finland is one of the few countries with a population-based twin registry $[16,17]$, it offers a unique opportunity to provide essential unbiased data on diabetes among twins. The objective of the present study was to estimate the concordance rate for Type 1 and Type 2 diabetes among the adult twin pairs separately for monozygotic and dizygotic twins.

\section{Subjects and methods}

The Finnish Twin Cohort was compiled from the Central Population Registry of Finland using selection procedures described elsewhere (16-18). In brief, the Central Population Registry of Finland is a computerized and centralized data bank of personal information on all Finnish citizens from 1967 onwards. To identify twin pairs, we selected all sets of persons with the same birth date, same sex, same 
surname at birth and same local community of birth. This yielded all pairs ( $n=17,357$ pairs) of same-sex adult twins born in Finland before 1958 with both co-twins alive in 1967 as well as a small number of subjects who satisfied these criteria, but who were not biological twins. A baseline questionnaire, administered in August through October 1975, asked whether the subjects were twins including questions for zygosity classification (see below). The questionnaire also contained medical and psychosocial questions. The overall response rate was $89 \%$. Further inquiries of local parish records were made of all non-repondents and conflicting responses to determine twinship.

The questions used to assign zygosity of twins were similar to those employed in questionnaires of other large twin samples [1924]; within the Finnish cohort, their validity was confirmed by bloodtyping a subsample of 104 twin pairs living in the Helsinki area [19]. About $93 \%$ of all responding pairs were classified as monozygotic or dizygotic with only a $1.7 \%$ probability of misclassification. A total of $13,888(4,307$ monozygotic and 9,581 dizygotic) pairs, who were 18 years of age or older at baseline were identified.

A total of 3,469 pairs were left unclassified by zygosity. These consisted of pairs, where both twins had died between 1967 and 1975, or they had an unknown address or did not reply to the 1975 questionnaire. In addition the algorithm for classifying zygosity left $7 \%$ of pairs unclassified because of conflicting responses to the items [24].

\section{Hospital discharge data}

The National Agency for Welfare and Health, (formerly the National Board of Health, Finland) has kept a national registry of hospital discharges since 1969. This registry covers all discharges of inpatients from all hospitals in Finland using the manual of the International Classification of Diseases. The diagnoses have been assigned by those physicians who treated the patient. Up to four different diagnoses per patient could be listed at each discharge. For the years 1972-1985, these data were linked with the Twin Cohort using a unique social security identification number assigned to each Finnish citizen. For the present study, an individual was considered to be diabetic if any of the discharge diagnosis codes was 250 (diabetes mellitus).

\section{Registry of the Social Insurance Instituiton for the reimbursement of free-of-charge medication}

In Finland, patients with diabetes are provided with anti-diabetic drug therapy free of charge. The prerequisite for such free medication is the patient's application, based on a detailed medical certificate, which must be approved by the Social Insurance Institution. The Institution keeps a registry of all persons who are provided with free-of-charge medication. This registry is virtually complete with regard to the patients with Type 1 diabetes. However, the registry is incomplete for Type 2 diabetic patients because a large number of these patients are treated with diet only, for at least some time after their diagnosis, and thus are not included in the drug registry [25]. The social security number enabled the twin cohort to be linked to the free-of-charge drug registry with a starting date for the reimbursement of drug costs for diabetes during the years 1964-1987.

\section{Classification of diabetes}

While the validity of the Finnish nationwide medical registries has been found to be satisfactory for identification of cases with specific diagnoses in epidemiological studies [26], information concerning different types of diabetes has not been included in the computerized records of the hospital discharge registry nor the drug registry. Therefore, copies of original records for all subjects with diabetes were obtained and reviewed in order to classify the type of diabetes.

Copies of the certificates of application for free-of-charge medication for diabetes, identified through the drug registry, were obtained from the local offices of the Social Insurance Institution. For patients identified through the National Hospital Discharge Registry copies were obtained of the hospital records indicating the first and the latest hospitalization because of diabetes. If the mode of treatment for diabetes had been changed, data related to such changes were also collected from the appropriate hospital records. Copies of death-certificates of the deceased were also collected.

The classification of diabetes was based on the current WHO criteria [27]. All individual records were reviewed independently without knowledge of the zygosity status or the identity of the cotwin. Those patients who had an abrupt onset of the disease and required insulin therapy from the time of diagnosis were classified as having idiopathic Type 1 diabetes, provided no other primary disease had been identified. Those patients who had only received oral anti-diabetic drugs or dietary therapy for diabetes or both, were classified as having Type 2 diabetes. All diabetic patients with ambiguous information concerning the type of therapy and the cases where the treatment modality had varied were subjected to a detailed review independently completed by two of the author-investigators (J.T. and J.E.). Any discrepancies were resolved by an additional review of the records. The diagnosis of Type 1 diabetes was accepted if the development of insulin dependency was clearly demonstrated and documented by the clinical findings in the hospital records. Patients in whom insulin therapy had been implemented as an adjuvant treatment to oral hypoglycaemic drugs to improve metabolic control were classified as Type 2 diabetic. Women who had been diagnosed with diabetes during pregnancy with a documented postpartum normal glucose tolerance were classified with gestational diabetes. In the same manner, patients with a diagnosed unequivocal primary cause for diabetes, such as pancreatitis or steroid therapy, were classified as having secondary diabetes. Hospital records of patients who were not on drug therapy, yet had an assigned diagnosis of diabetes due to increased blood glucose levels during hospitalization were screened further. If the blood glucose levels had been elevated but did not meet the current WHO criteria for diabetes, the patients were classified as having an impaired glucose tolerance. In order to avoid potential misclassification, records of those twin pairs where one twin had been assigned as Type 1 diabetic and the other as Type 2 diabetic were evaluated simultaneously. Using this method a discrepancy was confirmed in five twin pairs (two monozygotic and three dizygotic).

Among the 27,776 twins with known zygosity in the Finnish Twin Cohort, 738 were classified as diabetic during the study period: 539 were hospitalized with a diagnosis of diabetes, 445 had free-ofcharge medication, and 262 were registered on both registries (277 only on the former and 183 only on the latter). Diabetes was found to be an underlying cause of death in 16 co-twins who died between 1975-1985. All of the deceased diabetic twins had also been registered on the hospital discharge registry.

The availability of these two data sources for case-ascertainment made it possible to estimate the completeness of the overall case-ascertainment and the true number of diabetic cases in the twin cohort using the capture-mark-recapture method [28,29]. The estimated real number of diabetic twins was $915(95 \%$ confidence interval (CI) 864 to 966$)$. The point prevalence of diabetes was $3.3 \%(95 \% \mathrm{CI}$ $3.1 \%$ to $3.5 \%$ ). The estimated completeness of cases in our present study was $80.7 \%$ (95\% CI $76.4 \%$ to $85.4 \%$ ). The completeness calculated this way reflects, to a large extent, Type 2 diabetic patients treated with diet alone, because not every diabetic subject who is hospitalized in Finland requires or receives antidiabetic drug therapy. Although some of the diet-treated diabetic patients have been included in our present material among the hospitalized cases, our method of case-ascertainment has obviously missed many mild Type 2 diabetic subjects who were treated with diet alone and who were not hospitalized for any reason during 1972-1985.

\section{Statistical analysis}

The cumulative incidence of diabetes was calculated separately by gender and zygosity for the twins in the $28-39,40-49,50-59,60-69$, $70-79$ and 80 year and over age groups, respectively (age calculated 
Table 1. Cumulative incidence (\%) of diabetes mellitus in twins by age, sex and zygosity. The total number of individuals with diabetes was 738

\begin{tabular}{|c|c|c|c|c|c|c|c|c|c|c|c|}
\hline \multirow[t]{3}{*}{ Birth year } & \multirow{3}{*}{$\begin{array}{l}\text { Age in } 1985 \\
\text { (years) }\end{array}$} & \multicolumn{10}{|c|}{ Cumulative incidence } \\
\hline & & \multirow[t]{2}{*}{ Men } & \multirow[t]{2}{*}{ Women } & \multicolumn{4}{|c|}{ Monozygotic } & \multicolumn{4}{|c|}{ Dizygotic } \\
\hline & & & & Type 1 & Type 2 & Other & All & Type 1 & Type 2 & Other & All \\
\hline 1946-1957 & $28-39$ & 0.6 & 1.2 & 0.4 & 0.03 & 0.5 & 0.9 & 0.5 & 0.04 & 0.4 & 0.9 \\
\hline $1936-1945$ & $40-49$ & 1.4 & 1.0 & 0.2 & 0.8 & 0.5 & 1.5 & 0.4 & 0.4 & 0.3 & 1.1 \\
\hline $1926-1935$ & $50-59$ & 3.3 & 1.9 & 0.2 & 0.7 & 0.7 & 1.6 & 0.5 & 2.3 & 0.2 & 3.0 \\
\hline $1916-1925$ & $60-69$ & 5.9 & 6.3 & 0.4 & 6.0 & 0.2 & 6.6 & 0.4 & 5.0 & 0.5 & 5.9 \\
\hline $1906-1915$ & $70-79$ & 7.5 & 10.8 & 0.2 & 8.7 & 1.2 & 10.1 & 0.2 & 7.9 & 0.9 & 9.0 \\
\hline-1905 & $80+$ & 5.9 & 12.3 & 0.3 & 11.7 & 0.9 & 12.9 & 0.2 & 6.9 & 0.7 & 7.8 \\
\hline \multicolumn{3}{|c|}{ Total number of individuals 13,910} & 13,866 & & & & 8,614 & & & & 19,162 \\
\hline \multirow{5}{*}{\multicolumn{2}{|c|}{$\begin{array}{l}\text { Number of } \\
\text { diabetic patients } \\
\text { Type } 1 \\
\text { Type } 2 \\
\text { Gestational } \\
\text { Secondary }\end{array}$}} & 324 & 414 & & & & 247 & & & & 491 \\
\hline & & 57 & 52 & & & & 26 & & & & 83 \\
\hline & & 227 & 278 & & & & 171 & & & & 334 \\
\hline & & - & 46 & & & & 19 & & & & 27 \\
\hline & & 15 & 9 & & & & 9 & & & & 15 \\
\hline \multicolumn{2}{|c|}{ Impaired glu- } & 16 & 22 & & & & 18 & & & & 20 \\
\hline \multicolumn{2}{|c|}{ Unclassified } & 9 & 7 & & & & 4 & & & & 12 \\
\hline
\end{tabular}

as of 1985). These age groups correspond to the birth cohorts born in 1946-1957, 1936-1945, 1926-1935, 1916-1925, 1906-1915 and 1905 or earlier (Table 1). Subjects who did not meet the criteria for Type 1 or Type 2 diabetes were not included in the further analyses.

Concordance was assessed using two concordance rates, each calculated separately for monozygotic and dizygotic twin pairs [30, 31]. These are called rates in the twin literature, but are in reality ratios. Pairwise analyses were completed separately for Type 1 and Type 2 diabetes. To allow for comparison with earlier studies, where the number of unaffected pairs was unknown, the concordance rate was computed by both the probandwise and the pairwise method [31]. Each case was ascertained independently in this study and none were ascertained through a proband partner. Under such ascertainment conditions, the two concordance rates are a simple function of each other [31]. Pairwise concordance rates give the proportion of affected pairs that are concordant and are descriptive statistics. The probandwise concordance rate is the proportion of all probands that belong to concordant pairs and is informative of the recurrence risk of disease (corresponding to cumulative risk) associated with the degree of relationship of the pair. These can be compared to the risk of disease in the background population.

When the number of unaffected twin pairs in the population or the population rate of disease is known, various models can be used to estimate the contribution of genetic factors to the susceptibility to diabetes. For complex disease, the polygenic, multifactorial model is most frequently used. It assumes that there is normally distributed liability to disease. When a certain level or threshold of liability is reached, the disease becomes manifest [31]. Both genes and environmental factors are assumed to contribute to the liability and they result from the joint effects of many genes with small effects and a multitude of environmental effects. These assumptions were considered reasonable for this analysis based on prior knowledge of the genetic and environmental determinants of Type 1 and Type 2 diabetes.

Finally, we used structural equation modelling techniques with the $\mathrm{MX}$ software package [32] to estimate the variance components and to compare different genetic models. The MX software package is comparable to the widely-used LISREL software programmed for twin analyses [33]. Using these techniques, threshold models with additive genetic (A), dominance (D), shared environmental (C) or unique environmental $(\mathrm{E})$ sources of variation in the underlying liability to disease can be fitted to the 2 by 2 contingency tables (disease present/absent in twin 1 vs disease present/absent in twin 2) [32,33]. The contingency tables are set out for each type of diabetesseparately for monozygotic and dizygotic pairs. This could be done separately by sex for Type 2 diabetes where sufficient numbers of affected pairs were available, but not for Type 1 diabetes. The correlation in disease liability between the two members of each kind of twin pair is obtained as the tetrachoric correlation; the tetrachoric correlation is the correlation of a bivariate normal distribution that duplicates the cell probabilities from a 2 by 2 contingency table. In the structural equation models, parameter estimates and goodness-of-fit statistics are computed as described in detail elsewhere $[33,34]$. The goodness-offit statistics assess the degree to which the model specified by the investigators adequately corresponds to the data; a small goodness-offit chi-squared value and high $p$-value indicates good correspondence between the model and data. Alternative models that specify different components of variance can be compared by assessing the change in chi-square relative to changes in the degrees of freedom between models [34]. This permits the assessment of the significance of additive genetic effects and shared environmental effects to the variation of disease susceptibility in the population. Heritability is a population-specific parameter, which gives the proportion of overall, phenotypic variance attributable to genetic factors [31].

\section{Results}

The number of diabetic subjects was 247 among monozygotic twins and 491 among dizygotic twins (Table 1), the majority with Type 2 diabetes. Gestational diabetes was found in 46 female twins, and secondary diabetes (usually following acute or chronic pancreatitis) was discovered in 24 twins. There were 54 patients identified through the hospital records, who had received no antidiabetic drug therapy, and where the diagnosis of diabetes remained uncertain after the review of all available records. Of these, 38 met the WHO criteria for impaired glucose tolerance, and it was not possible to classify the diabetes status of 16 subjects using the current diagnostic criteria.

The cumulative incidence of diabetes was $1.4 \%$ in men and $1.3 \%$ in women aged $28-59$ years; but it was higher in women than men in the age group of 60 years or over $(9.3 \%$ vs $7.0 \%, p<0.01)$ (Table 1$)$. The age-adjusted cumulative incidence did not differ between monozygotic and dizygotic twins. The monozygotic/dizygotic ratio in 
Table 2. Number of concordant and discordant pairs and concordance rates for Type 1 (insulin-dependent) diabetes by gender and zygosity

\begin{tabular}{|c|c|c|c|c|c|c|c|}
\hline \multirow[t]{2}{*}{ Gender } & \multirow[t]{2}{*}{ Zygosity } & \multirow{2}{*}{$\begin{array}{l}\text { Concordant } \\
\text { pairs }\end{array}$} & \multirow{2}{*}{$\begin{array}{l}\text { Discordant } \\
\text { pairs }\end{array}$} & \multicolumn{2}{|c|}{ Concordance rate } & \multirow[t]{2}{*}{ Number of cases } & \multirow[t]{2}{*}{ Persons at risk } \\
\hline & & & & Probandwise & Pairwise & & \\
\hline \multirow[t]{2}{*}{$\overline{\text { Men }}$} & $\mathrm{MZ}$ & 1 & 9 & 0.182 & 0.100 & 11 & 4,100 \\
\hline & $\mathrm{DZ}$ & 0 & 46 & 0.000 & 0.000 & 46 & 9,810 \\
\hline \multirow[t]{2}{*}{ Women } & $\mathrm{MZ}$ & 2 & 11 & 0.267 & 0.154 & 15 & 4,514 \\
\hline & DZ & 2 & 33 & 0.054 & 0.057 & 37 & 9,352 \\
\hline \multirow[t]{2}{*}{ All } & $\begin{array}{l}\mathrm{MZ} \\
(95 \% \mathrm{CI})\end{array}$ & 3 & 20 & $\begin{array}{l}0.231 \\
(0.09 \text { to } 0.44)\end{array}$ & $\begin{array}{l}0.130 \\
(0.03 \text { to } 0.34)\end{array}$ & 26 & 8,614 \\
\hline & $\begin{array}{l}\mathrm{DZ} \\
(95 \% \mathrm{Cl})\end{array}$ & 2 & 79 & $\begin{array}{l}0.048 \\
(0.01 \text { to } 0.12)\end{array}$ & $\begin{array}{l}0.025 \\
(0.003 \text { to } 0.09)\end{array}$ & 83 & 19,162 \\
\hline
\end{tabular}

MZ, Monozygotic pairs; $\mathrm{DZ}$, dizygotic pairs; $\mathrm{CI}$, confidence interval

Table 3. Results from fitting threshold models to Type 1 (insulin-dependent) diabetes data in the Finnish Twin Cohort

\begin{tabular}{lllllllllll}
\hline & \multicolumn{3}{c}{ Components of variance } & & \multicolumn{3}{c}{ Goodness-of-fit tests } \\
\cline { 2 - 4 } \cline { 7 - 9 } Model & $\mathrm{A}$ & $\mathrm{C}$ & $\mathrm{D}$ & $\mathrm{E}$ & & chi $^{2}$ & $d f$ & $p$-value & AIC \\
\hline A, C, E & 0.757 & 0.00 & - & 0.243 & & 2.34 & 3 & 0.50 & -3.66 \\
A, E & 0.757 & - & - & 0.243 & & 2.34 & 4 & 0.67 & -5.66 \\
A, D, E & 0.664 & - & 0.10 & 0.236 & & 2.31 & 3 & 0.51 & -3.69 \\
E & - & - & - & 1.0 & 30.5 & 5 & $<0.001$ & 20.5 \\
\hline
\end{tabular}

A, Additive genetic effects; $\mathrm{C}$, shared (family) environmental effects; D, effects due to dominance; $E$, unshared environmental effects; AIC, Akaike's information criterion is a statistic, which combines information on the goodness-of-fit and the simplicity of the model [34]. The best model is thus generally the one with a lowest AICvalue

incidence of Type 1 diabetes was 0.90 (95\% CI 0.75 to $1.09)$ and in incidence of Type 2 diabetes 1.43 (95\% CI 0.92 to 2.22 ).

The vast majority of the 104 twin pairs with one Type 1 diabetic twin was discordant for diabetes (Table 2). The concordance rate was clearly higher among monozygotic than dizygotic twins, but even in monozygotic twins it was quite low, being $23 \%$ probandwise and $13 \%$ pairwise. The correlation in liability for Type 1 diabetes in monozygotic twins was 0.727 (S.E. 0.11). Among dizygotic pairs the correlation was 0.359 (S.E. 0.13). A model with environmental effects only fitted the data poorly (Table 3 ) with a goodness-of-fit chi-square of $30.5(p<0.001)$, while all the remaining models fitted the data equally well. The best fitting model was the simple model with additive genetic $(\mathrm{A})$ and unshared environmental effects (E). Effect due to dominance (D) in the ADE model was about $10 \%$ whereas the additive genetic effects were $66 \%$. Shared (family) environmental effects (C) were small. The overall concordance rate for Type 2 diabetes (34\% probandwise) was higher in monozygotic twins than that for Type 1 diabetes and among dizygotic twins it was $16 \%$ (Table 4). The concordance rate was slightly higher among women than men. The highest concordance rate was found among monozygotic women aged 60 years or over, $40.4 \%$ probandwise and $25 \%$ pairwise. The correlations in liability for Type 2 diabetes were some what higher among women than men for both monozygotic and dizygotic pairs with an overall correlation of 0.726 in monozygotic and 0.50 in dizygotic pairs (Table 5).
Table 6 summarizes the results of the model fitting procedures to the Type 2 diabetes data. For men both the AE and ACE models fit the data adequately. The proportion of variance attributable to additive genetic effects was $48 \%$ in the ACE model and $69 \%$ in the A E model, which was the best fitting one (AE model vs ACE model: $\Delta \chi_{1}^{2}=1.01, p=0.32$ ). Among women, the ACE model fitted significantly better than the AE model $\left(\Delta \chi_{1}^{2}=6.84\right.$, $p=0.009$ ) yielding an estimate for additive genetic effects (A) of $38 \%$ and shared environmental effects (C) $37 \%$. Based on the AE model the heritability for Type 2 diabetes was $79 \%$.

To test for heterogeneity of effects across gender, we combined the data and fit models. If we assume the threshold to be different in men and women, the ACE models fit better than assuming equal thresholds for both sexes (model 7 vs model $5 \Delta \chi_{1}^{2}=3.57, p=0.059$ ), though the difference was not statistically significant. The male threshold was higher than the female threshold refecting the higher incidence of Type 2 diabetes in women. The AE model assuming the threshold to be different in men and women fit somewhat better than the model assuming equal thresholds for both sexes (model 8 vs model $6 \Delta \chi_{1}^{2}=3.74, p=0.053$ ), though the difference was not statistically significant. All models combining men and women gave adequate fits (Table 6). Tests for heterogeneity of gender effects were not significant (for ACE-models $\Delta \chi_{3}^{2}$, homogeneity $=6.46, p=0.091$ ). Finally, we also fitted $A E$ and $A C E$ models to the Type 2 diabetes data with two age-group-specific thresholds, because the incidence of Type 2 diabetes was higher in subjects aged 60 years or more than in younger subjects. Both models had similar $p$-values, but the Akaike's information criterion for the AE was slightly smaller, suggesting that this simpler model fit the data better. The proportion of variance in liability due to genetic factors under this AE model was 0.64 and under the ACE model it was 0.47 .

\section{Discussion}

The results from our population-based twin study showed that the notion of a possible selection bias in previous studies of diabetes in twins leading to too high concord- 
Table 4. Number of concordant and discordant pairs and concordance rates for Type 2 (non-insulin-dependent) diabetes by age, gender and zygosity

\begin{tabular}{|c|c|c|c|c|c|c|c|c|}
\hline \multirow[t]{2}{*}{ Gender } & \multirow[t]{2}{*}{ Zygosity } & \multirow{2}{*}{$\begin{array}{l}\text { Age group } \\
\text { (years) }\end{array}$} & \multirow{2}{*}{$\begin{array}{l}\text { Concordant } \\
\text { pairs }\end{array}$} & \multirow{2}{*}{$\begin{array}{l}\text { Discordant } \\
\text { pairs }\end{array}$} & \multicolumn{2}{|c|}{ Concordance rate } & \multirow{2}{*}{$\begin{array}{l}\text { Number of } \\
\text { cases }\end{array}$} & \multirow{2}{*}{$\begin{array}{l}\text { Persons } \\
\text { at risk }\end{array}$} \\
\hline & & & & & Probandwise & Pairwise & & \\
\hline \multirow[t]{6}{*}{ Men } & $\mathrm{MZ}$ & $28-59$ & 3 & 13 & 0.316 & 0.188 & 19 & \\
\hline & & $60+$ & 7 & 39 & 0.264 & 0.152 & 53 & \\
\hline & & Total & 10 & 52 & 0.278 & 0.161 & 72 & 4,100 \\
\hline & $\mathrm{DZ}$ & $28-59$ & 3 & 54 & 0.100 & 0.053 & 60 & \\
\hline & & $60+$ & 6 & 83 & 0.126 & 0.067 & 95 & \\
\hline & & Total & 9 & 137 & 0.116 & 0.062 & 155 & 9,810 \\
\hline \multirow[t]{6}{*}{ Women } & $\mathrm{MZ}$ & $28-59$ & 0 & 5 & 0.000 & 0.000 & 5 & \\
\hline & & $60+$ & 19 & 56 & 0.404 & 0.253 & 94 & \\
\hline & & Total & 19 & 61 & 0.384 & 0.238 & 99 & 4,514 \\
\hline & $\mathrm{DZ}$ & $28-59$ & 0 & 29 & 0.000 & 0.000 & 29 & \\
\hline & & $60+$ & 18 & 114 & 0.240 & 0.136 & 150 & \\
\hline & & Total & 18 & 143 & 0.203 & 0.112 & 179 & 9,352 \\
\hline \multirow[t]{2}{*}{ All } & $\mathrm{MZ}$ & & 29 & 113 & 0.339 & 0.204 & 171 & 8,614 \\
\hline & $\begin{array}{l}\mathrm{DZ} \\
(95 \% \mathrm{CI})\end{array}$ & & 27 & 280 & $\begin{array}{l}0.162 \\
(0.12 \text { to } 0.20)\end{array}$ & $\begin{array}{l}0.088 \\
(0.06 \text { to } 0.13)\end{array}$ & 334 & 19,162 \\
\hline
\end{tabular}

$\mathrm{MZ}$, Monozygotic pairs; $\mathrm{DZ}$, dizygotic pairs; $\mathrm{CI}$, confidence interval

Table 5. Correlations in liability for developing Type 2 (non-insulindependent) diabetes in Finnish monozygotic and dizygotic twins

\begin{tabular}{lll}
\hline & $\begin{array}{l}\text { Monozygotic } \\
\text { twin pairs }\end{array}$ & $\begin{array}{l}\text { Dizygotic } \\
\text { twin pairs }\end{array}$ \\
\hline Men & $0.669(0.08)$ & $0.418(0.08)$ \\
Women & $0.761(0.05)$ & $0.557(0.04)$ \\
All & $0.726(0.04)$ & $0.500(0.05)$ \\
\hline
\end{tabular}

Values shown are correlation coefficients (standard error)

ance rates, as suggested by some of the investigators themselves, is appropriate $[10,35,36]$. The pairwise concordance rate for Type 1 diabetes in the Finnish twin cohort was $13 \%$ and $2.5 \%$ among monozygotic and dizygotic twins, respectively. The observed concordance in the prospective diabetic twin study in the UK was $34 \%$ when the median age was 30 years and the median follow-up time was 12 years [10]. In preliminary data from an ongoing twin study in the United States, the pairwise concordance for diabetes was about $29 \%$ [37]. We believe that our study has overcome the problem of overselection of the concordant pairs, which is probably the main reason for the lower concordance rate in comparison with the earlier studies mentioned. Based on the approval of formal application to the Social Insurance Institution, diabetes drug treatment has been free of charge to patients in Finland since 1965 . Virtually all Type 1 diabetic patients and a large proportion of Type 2 diabetic patients (i.e. those being treated with oral antidiabetic agents) apply for this benefit resulting in a high degree of case-ascertainment based on the drug registry. Therefore, it is likely that our estimates for concordance among monozygotic twins are very close to reality. However, we should be careful when interpreting the results of our study, also, because the number of concordant pairs for Type 1 diabetes was relatively small and because there was the possibility of a selective underestimation of mild cases of Type 2 diabetes.
Less data exist about the concordance for Type 1 diabetes among dizygotic twins. In a recent nationwide study of childhood diabetes in Finland, the prevalence of Type 1 diabetes among the siblings of Type 1 diabetic probands was about $3 \%$ at the time of the diagnosis of the proband [38] increasing to $5 \%$ after a 3-year follow-up. Generally, one would assume that the concordance rate among dizygotic twins might resemble the usual risk found among siblings, which was also found in our study.

Up to now, data on putative genetic and environmental factors for Type 1 diabetes have not been systematically investigated among diabetic twin pairs, with the exception of a number of reports from a twin study in the UK [39]. The results of that study suggest that co-twins of twin pairs under 15 years of age and possessing HLA-DR3 and DR4 antigens may have a higher concordance rate for Type 1 diabetes. The results from the UK suggest that a diabetogenic process may have been initiated in non-diabetic co-twins which for some reason has not led to Beta-cell destruction [40]. These findings need to be confirmed in a population twin-based study. Finland has the highest incidence of Type 1 diabetes. If this is due to a very strong environmental exposure unmasking the underlying genetic susceptibility responsible for this excess in incidence, an increased concordance for Type 1 diabetes among monozygotic twins should also be seen. However, this was not the case. On the other hand, if the genetic susceptibility to Type 1 diabetes had a higher penetrance in Finland than for instance in the UK, an increased concordance would be seen in Finland. Thus, additional research on the genetic-environmental interaction in the development of Type 1 diabetes among twins in Finland is necessary.

The method of creating the Finnish twin cohort required that both of the co-twins were alive in 1967. If a diabetic twin had died prior to this date, the twin pair was not included in the cohort. This reduced the number of diabetic subjects in the cohort, but as selective mortality 
Table 6. Results of fitting threshold models to Type 2 (non-insulin-dependent) diabetes data in the Finnish Twin Cohort

\begin{tabular}{|c|c|c|c|c|c|c|c|}
\hline \multirow[b]{2}{*}{ Model } & \multicolumn{3}{|c|}{ Components of variance } & \multicolumn{4}{|c|}{ Goodness-of-fit tests } \\
\hline & A & $\mathrm{C}$ & $\mathrm{E}$ & $\operatorname{chi}^{2}$ & $d f$ & $p$-value & AIC \\
\hline \multicolumn{8}{|l|}{ Men } \\
\hline$A, C, E$ & 0.480 & 0.183 & 0.337 & 0.46 & 3 & 0.93 & -5.54 \\
\hline $\mathrm{A}, \mathrm{E}$ & 0.692 & - & 0.308 & 1.47 & 4 & 0.83 & -6.53 \\
\hline \multicolumn{8}{|l|}{ Women } \\
\hline $\mathrm{A}, \mathrm{C}, \mathrm{E}$ & 0.381 & 0.373 & 0.246 & 0.94 & 3 & 0.82 & -5.06 \\
\hline $\mathrm{A}, \mathrm{E}$ & 0.794 & - & 0.206 & 7.80 & 4 & 0.10 & -0.20 \\
\hline \multicolumn{8}{|c|}{ All subjects (combined data, equal thresholds for both genders) } \\
\hline $\mathrm{A}, \mathrm{C}, \mathrm{E}$ & 0.424 & 0.295 & 0.282 & 7.87 & 9 & 0.55 & -10.13 \\
\hline $\mathrm{A}, \mathrm{E}$ & 0.756 & - & 0.244 & 14.79 & 10 & 0.14 & -5.21 \\
\hline \multicolumn{8}{|c|}{ All subjects (combined data, gender-specific thresholds) } \\
\hline $\mathrm{A}, \mathrm{C}, \mathrm{E}$ & 0.427 & 0.292 & 0.282 & 4.30 & 8 & 0.83 & -11.70 \\
\hline $\mathrm{A}, \mathrm{E}$ & 0.756 & - & 0.244 & 11.05 & 9 & 0.27 & -6.95 \\
\hline \multicolumn{8}{|c|}{ All subjects (age-specific thresholds for $28-59$ years and $60+$ years) } \\
\hline $\mathrm{A}, \mathrm{C}, \mathrm{E}$ & 0.465 & 0.150 & 0.385 & 11.26 & 8 & 0.19 & -4.74 \\
\hline A, E & 0.643 & 0.000 & 0.357 & 12.57 & 9 & 0.18 & -5.43 \\
\hline
\end{tabular}

A, Additive genetic effects; $C$, shared (family) environmental effects; D, effects due to dominance; $E$, unshared environmental effects; AIC, Akaike's information criterion is a statistic, which combines information on the goodness-of-fit and the simplicity of the model [34]. The best model is thus generally the one with a lowest AIC value

should be similar for concordant and discordant pairs concordance rates should not be affected. On the other hand, we could not avoid the underestimation of diabetic subjects in the present study where our data sources were limited to the hospital records and to the documents of the Central Drug Registry. Thus, a considerable number of diabetic patients treated with diet alone and those who were unaware of their diabetes were missed.

Twin data are used to measure the relative importance of heredity and environment on the development of specific quantitative traits. In a narrow sense, heritability considers the additive portion of the genetic variability in relation to the phenotypic variability [41, 42]. The formulae for estimating heritability are based on the differential in concordance rates among monozygotic and dizygotic twins. Heritability estimates previously have not been given separately for Type 1 and Type 2 diabetes. In two earlier studies, heritability of diabetes was found to decrease with the increasing age of onset of diabetes [43,44], suggesting a higher heritability for Type 1 diabetes which has a younger age at onset than does Type 2 diabetes. For the first time, our present results provide a heritability estimate for Type 1 diabetes which was relatively high (0.736), suggesting that Type 1 diabetes has a very strong genetic component. This is in agreement with the present knowledge about the genetics of Type 1 diabetes [45]. The major genetic susceptibility to Type 1 diabetes is conferred by a gene or genes in the HLA region [45-48]. A linkage between the HLA system and the putative gene coding for susceptibility to Type 1 diabetes has been clearly shown in studies of affected siblings $[49,50]$. Family studies show that over $10 \%$ of HLA identical siblings of children with Type 1 diabetes also develop Type 1 diabetes, the risk among HLA-haploidentical siblings is intermediate and virtually zero in HLA-non-identical siblings [47]. Heritability estimates may depend on the oc- currence of the disease and therefore vary between populations. In addition, heritability estimates, based solely on the comparison of similarity of monozygotic and dizygotic pairs with respect to a certain disease, tend to overestimate the genetic component as the correlation of environmental factors is higher among monozygotic than dizygotic co-twins [49-53].

Although the observed concordance rate for Type 2 diabetes was higher than that for Type 1 diabetes in this study, it was considerably lower than in the earlier twin studies of Type 2 diabetes [7, 10]. These studies which were all relatively small in size (the largest series comprising only 85 pairs with a Type 2 diabetic twin [10] ) have reported concordance from $55 \%$ to $100 \%$ among monozygotic twins, while in our study it was $40 \%$ and at the most $55 \%$ to $100 \%$. Concordance was overestimated because the diabetic twin pairs were usually identified through a diabetic proband. It is well-known that the pairs concordant for a disease are more likely to participate in twin studies than discordant pairs. Only the study by Newman et al. [7] has partially overcome this problem, but their male twin cohort was very small (only 250 monozygotic and 264 dizygotic pairs) examined twice at mean ages of 47 and 57 years, respectively. They reported probandwise concordances for Type 2 diabetes of $28.6 \%$ among monozygotic twins and $14.3 \%$ among dizygotic twins at the first examination. The estimates are quite similar to our results among the Finnish male twins aged 2859 years: $31.6 \%$ among monozygotic and $10.0 \%$ among dizygotic twins.

The diagnosis of Type 2 diabetes in this study was based on the use of oral antidiabetic drugs or hospital admission with diabetes as a diagnosis, or both. The validity of diagnosis was confirmed by a review of medical records which was independently completed by two of the authors. Patients identified in this way most likely have 
diabetes which is either moderate or severe. The high concordance rate for Type 2 diabetes in earlier studies has been speculated as being partially due to a bias in clinicbased studies to include more severe cases. The age-specific cumulative incidence in this twin cohort was slightly lower than the known prevalence of diabetes in Finland but in agreement with the known prevalence after correcting the observed prevalence among twins using the capture-mark-recapture method $[15,16,25,54]$. One might argue that we should have tested the non-diabetic cotwins for glucose intolerance. However, ascertainment through a proband partner would have resulted in a bias leading to overestimation of concordance rates, if nondiabetic twin pairs were not tested in the same way. Additional testing in co-twins would have also invalidated the calculation of the probandwise concordance rate.

Unlike all other previous diabetic twin studies this study was also able to include those twins who had died since the twin cohort had been defined. All 19 patients with diabetes listed among the diagnoses on the death certificate, were also found to be diabetic through the hospital discharge registry. The concordance rate did not increase with age among men, which indicated that the concordance may not increase with a longer follow-up. This is in agreement with the findings from other studies which suggest that the interval for the other co-twin to develop Type 2 diabetes is usually not very long $[7,10]$. In the UK twin study with 48 diabetic pairs, 35 became concordant within 5 years [7]. In the American study, only one of 15 originally discordant monozygotic pairs remained discordant for Type 2 diabetes during the 10-year follow-up, but follow-up information was missing for six monozygotic pairs originally discordant for Type 2 diabetes [8].

Unfortunately, our study design did not permit metabolic studies among the co-twins of diabetic probands. In the UK twin study, all non-diabetic twins including five pairs discordant for Type 2 diabetes showed metabolic abnormalities and insulin deficiency similar to that seen in overt Type 2 diabetes [7]. Similarly in the 10-year followup examination of the American cohort, non-diabetic twin brothers of the Type 2 diabetic twins diagnosed after the first examination, had a significantly higher 1 -h postload blood glucose than other monozygotic non-diabetic twins [8]. Therefore, some of the non-diabetic twins in the present study may have met the current criteria for Type 2 diabetes [27], had they been tested for glucose intolerance. This may explain some of the relatively low concordance for Type 2 diabetes in our study in comparison with other studies where glucose tolerance has been tested for in both co-twins. In the future we will attempt to carry out metabolic investigations in a representative sample of our Finnish twin cohort.

The review of the hospital records revealed that there were five pairs concordant for diabetes - two monozygotic, three dizygotic - where one twin had Type 1 diabetes but the co-twin had Type 2 diabetes. If these pairs were included as diabetic pairs when computing the concordance rate, the concordance for Type 1 diabetes in particular would have been much higher: in monozygotic twins $21.7 \%$ and dizygotic twins $6.2 \%$ pairwise. It has been demonstrated that non-diabetic co-twins may have immune and metabolic changes associated with Type 1 diabetes without causing the disease [40]. It has also been suggested that the family history of Type 2 diabetes might be increased in children with Type 1 diabetes [55]. Such twin pairs concordant for diabetes but discordant for the type of diabetes have, however, not been described in earlier studies.

In conclusion, this population-based twin study of diabetes showed that genetic factors play a major role in the risk of developing Type 1 diabetes, whereas in Type 2 diabetes the environmental effects also seem to be important. Environmental effect may be a possible reason for the higher concordance rate for Type 2 diabetes than for Type 1 diabetes.

Acknowledgement. This study was supported by the grant from the Nordisk Insulinfond.

\section{References}

1. Diabetes epidemiology research international (1987) Preventing insulin dependent diabetes mellitus: the environmental challenge. Br Med J 295: 479-481

2. Kirk RL, Serjeantson SW, King H, Zimmet P (1985) The genetic epidemiology of diabetes mellitus. Prog Clin Biol Res 194: 119 146

3. Then Berg H (1938) Die erbbiologie des diabetes mellitus. Arch Rass Ges Biol 32: 289-340

4. Harvald B, Hauge M (1963) Selection in diabetes in modern society. Acta Med Scand 173: 459-465

5. Gottlieb MS, Root HF (1968) Diabetes mellitus in twins. Diabetes 17: 693-704

6. Barnett AH, Eff C, Leslie RDG, Pyke DA (1981) Diabetes in identical twins: a study of 200 pairs. Diabetologia 20:87-93

7. Newman B, Selby JV, King M-C, Slemenda C, Fabsitz R, Friedman GD (1987) Concordance for type 2 (non-insulin-dependent) diabetes mellitus in male twins. Diabetologia 30: 763-768

8. Committee on diabetic twins, Japan Diabetes Society (1988) Diabetes mellitus in twins: a cooperative study in Japan. Diabetes Res Clin Pract 5:271-280

9. Pyke DA (1988) Development of diabetes in identical twins. In: Camerini-Davalos RA, Cole H (eds) Early diabetes: prediabetes. Plenum Press, New York, pp 255-258

10. Rich SS (1990) Mapping genes in diabetes. Genetic Epidemiological Perspective. Diabetes 39:1315-1319

11. Romanov K, Koskenvuo M, Kaprio J, Sarna S, Heikkilä K (1990) Selection bias in disease-related twin studies data on 11,154 adult Finnish twin pairs from a nationwide panel. Acta Genet Med Gemellol 39: 441-446

12. Diabetes epidemiology research international group (1988) Geographic patterns of childhood insulin-dependent diabetes mellitus. Diabetes 37: 1113-1119

13. Rewers M, LaPorte RE, King HOM, Tuomilehto $\mathrm{J}$, for the diabetes epidemiology research international study group (DERI) (1988) Insulin-dependent diabetes mellitus in childhood: international patterns and trends. World Health Stat Q 41: 179-189

14. Reunanen A (1984) Prevalence and incidence of type II diabetes in Finland. Acta Endocrinol 5 [Suppl] 262: 31-35

15. Tuomilehto J, Nissinen A, Kivelä S-L et al. (1986) Prevalence of diabetes mellitus in elderly men aged 65 to 84 years in eastern and western Finland. Diabetologia 29:611-615

16. Koskenvuo M, Langinvainio H, Kaprio J, Rantasalo I, Sarna S (1979) The Finnish twin registry: baseline characteristics: section III: occupational and psychosocial factors. Publications of public health M49. University of Helsinki, Helsinki 
17. Kaprio J, Sarna S, Koskenvuo M, Rantasalo I (1978) Baseline characteristics of the Finnish twin registry section II: history of symptoms and illnesses, use of drugs, physical characteristics, smoking, alcohol and physical activity. Publications of public health M37. University of Helsinki, Helsinki

18. Kaprio J, Sarna S, Koskenvuo M, Rantasalo I (1978) The Finnish twin registry: formation and compilation, questionnaire study, zygosity determination procedures and research program. Prog Clin Biol Res 24B: 179-184

19. Sarna S, Kaprio J, Sistonen P, Koskenvuo M (1978) Diagnosis of twin zygosity by mailed questionnaire. Human Hered 28: $241-$ 254

20. Cederlöf R, Friberg L, Johansson E, Kaij L (1961) Studies on similarity diagnosis in twins with the aid of mailed questionnaires. Acta Genet Stat Med 11: 338-362

21. Harvald B, Hauge M (1965) Hereditary factors elucidated by twin studies. In: Nell JV, Shaw M, Schull WJ (eds) Genetics and the epidemiology of chronic disease. United States Department of Health, Education and Welfare, Washington, pp 61-76

22. Jablon S, Neel JV, Gershowitz H, Atkinson GF (1967) The NASNRC twin panel: methods of construction of the panel, zygosity diagnosis and proposed use. Am J Human Genet 19:133-161

23. Kasriel J, Eaves LJ (1976) A comparison of the accuracy of written questionnaires with blood-typing for diagnosing zygosity in twins. J Biosocial Science 8: 263-266

24. Sarna S, Kaprio J (1979) Dependency of concordance probability on gene frequencies in genetic systems for the diagnosis of twin zygosity. Acta Genet Med Gemello1 28: 133-137

25. Laakso M, Reunanen A, Klaukka T, Aromaa A, Maatela J, Pyörälä K (1991) Changes in the prevalence and incidence of diabetes mellitus in Finnish adults. Am J Epidemiol 9: 850-857

26. Heliövaara M, Reunanen A, Aromaa A et al. (1984) Validity of hospital discharge data in a prospective study on stroke and myocardial infarction. Acta Med Scand 216:309-316

27. World Health Organization study group report (1985) Diabetes mellitus. Technical reports series 727 . WHO, Geneva

28. Sekar CC, Deming WE (1949) On a method of estimating birth and death rates and the extent of registration. Am Stat Assoc J 44: $101-115$

29. Wittes JT, Colton T, Sidel VW (1974) Capture-recapture methods for assessing the completeness of case ascertainment when using multiple information. J Chronic Dis 27:25-36

30. Smith C (1974) Concordance in twins: methods and interpretation. Am J Hum Genet 26: 454-466

31. Emery AEH (1986) Methodology in medical genetics. An introduction to statistical methods. Livingstone, Edinburgh, pp 55-56

32. Neale MC (1991) MX: statistical modelling. Medical College of Virginia, Department of Human Genetics

33. Heath AC, Neale MC, Hewitt JK, Eaves LJ, Fulker DW (1989) Testing structural equation models for twin data using LISREL. Behav Genet 19: 9-28

34. Neale MC, Heath AC, Hewitt JK, Eaves LJ, Fulker DW (1989) Fitting genetic models with LISREL: hypothesis testing. Behav Genet 19:37-49

35. Tattersall RB, Pyke DA (1972) Diabetes in identical twins. Lancet II: $1120-1125$

36. Olmos P, A'Hern R, Heaton DA et al. (1988) The significance of the concordance rate for type 1 (insulin-dependent) diabetes in identical twins. Diabetologia 31: 747-750

37. Kumar D, Gemayel NS, Gill SK et al. (1988) Type-specific concordance in young diabetic monozygotic twins. Adv Exp Med Biol 246: 259-267

38. Tuomilehto J, Lounamaa R, Tuomilehto-Wolf E et al. (1992) Epidemiology of childhood diabetes in Finland - background of a nationwide study of type 1 (insulin-dependent) diabetes mellitus. Diabetologia 35: 70-76

39. Johnston C, Pyke DA, Cudworth AG, Wolf E (1983) HLA-DR typing in identical twins with insulin-dependent diabetes: a dif- ference between concordant and discordant pairs. Br Med J 286: 253-255

40. Millward BA, Alviggi L, Hoskins PJ et al. (1986) Immune changes associated with insulin dependent diabetes may remit without causing the disease: a study in identical twins. Br Med J 292:793-796

41. Bell AE (1977) Heritability in retrospect. J Hered 68: 297-300

42. Kang KW, Christian JC, Norton JA Jr (1987) Heritability estimates from twin studies. I. Formulae of heritability estimates. Acta Genet Med Gemellol 27:39-44

43. Falconer DS (1967) The inheritance of liability to diseases with variable age of onset, with particular reference to diabetes mellitus. Ann Hum Genet 31:1-20

44. Simpson NE (1969) Heritabilities of liability to diabetes when sex and age at onset are considered. Ann Hum Genet (Lond) 32: 283-303

45. Degnbol B, Green A (1978) Diabetes mellitus among first- and second-degree relatives of early onset diabetics. Ann Hum Genet $42: 25-47$

46. Cudworth A, Wolf E, Gorsuch A, Festenstein H (1979) A new look at HLA genetics with particular reference to Type 1 diabetes. Lancet II: 389--391

47. Tiwari JL, Terasaki PL (1985) HLA and disease associations. Springer, Berlin Heidelberg New York; $\mathrm{p} 185$

48. Wolf E, Spencer KM, Cudworth AG (1983) The genetic susceptibility to Type 1 (insulin-dependent) diabetes: analysis of the HLA-DR association. Diabetologia 24:224-230

49. Walker A, Cudworth AG (1980) Type 1 (insulin-dependent) diabetic multiplex families: mode of genetic transmission. Diabetes 29: 1036-1039

50. Wolf $\mathrm{E}$ (1988) Different linkage disquilibrium in Type 1 diabetic and "healthy" HLA haplotypes. In: Laron Z, Karp M (eds) Prognosis of diabetes in children. Pediatr Adolesc Endocrinol 18: 270-274

51. Kaprio J, Koskenvuo M, Langinvainio H, Romanov K, Sarna S, Rose RI (1987) Genetic influences on use and abuse of alcohol: a study of 5638 adult Finnish twin brothers. Alc Clin Exp Res 11: 349-356

52. Rose RJ, Koskenvuo M, Kaprio J, Sarna S, Langinvainio H (1988) Shared genes, shared experiences, and similarity of personality: data from 14,288 adult Finnish co-twins. J Personal Soc Psychol 54: 161-171

53. Sellers TA, Kushi LH, Potter JD (1991) Can dietary intake patterns account for the familial aggregation of disease? Evidence from adult siblings living apart. Genet Epidemiol 8: 105-112

54. Tuomilehto J, Korhonen H, Kartovaara L et al. (1991) Prevalence of diabetes mellitus and impaired glucose tolerance in the middle-aged population of three areas in Finland. Int J Epidemiol 20: 1010-1017

55. Dahlquist G, Blom L, Tuvemo T, Nyström L, Sandström A, Wall S (1989) The Swedish childhood diabetes study - results from a nine year case register and a one year case-referent study indicating that type 1 (insulin-dependent) diabetes mellitus is associated with both type 2 (non-insulin-dependent) diabetes mellitus and autoimmune disorders. Diabetologia 32:2-6

Received: 27 March 1992

and in revised form: $10 \mathrm{July} 1992$

Prof. J. Tuomilehto

National Public Health Institute

Department of Epidemiology and Health Promotion

Mannerheimintie 166

SF-00300 Helsinki

Finland 